Only a few of the viral variants associated with the human immunodeficiency virus (HIV) seem to be passed from an infected mother to her infant, according to research published in Science magazine (1992;255:1134-1136).

Molecular virologists at Chicago's Northwestern University Medical School, the Los Alamos (NM) National Laboratory, and the New York University School of Medicine analyzed multiple HIV-1 sequences from three motherinfant pairs. Specifically, they looked at sequences from the V3 and V4-V5 regions of the envelope gene.

They found that although the infected mother had numerous viral variants, her infant only had a subset of these variants. Each infant was missing the $\mathrm{N}$-linked glycosylation site, which was present in each mother. Furthermore, the variability in the sequencing was greater in each mother than in the infants, say researchers.

These results suggest that a selection process occurs, but researchers have yet to ascertain the mechanisms behind such selection.

"This finding could lead to new strategies for therapeutic intervention in the spread of the HIV from mother to fetus," says Steven M. Wolinsky, $\mathrm{PhD}$.

"This study is innovative and intriguing, but more re- search is needed to confirm the results," comments Lynne Mofenson, MD, an official at the National Institute of Child Health and Human Development, which oversees research on pediatric HIV infection and the acquired immunodeficiency syndrome.

New strategies for the acquired immunodeficiency syndrome (AIDS) have been issued by the World Health Organization (WHO).

The first revisions since 1987 , the new strategies reflect the increasing incidence of the human immunodeficiency virus (HIV) infection among women the world over. Michael Merson, MD, director of the WHO AIDS program said that the revisions were necessary because more HIVinfected persons will develop AIDS in the near future. By the year 2000 , say WHO officials, the number of women infected with the HIV will surpass the number of men infected with the virus.

Specifically, the new strategy will focus on:

- Frank advertising concerning how AIDS is sexually transmitted, with the message that only sexual abstinence or absolute fidelity prevents the risk of infection;

- The teaching of safe sex practices for preadolescent and teenage youngsters;
- The unenforcement of laws against adult male homosexuality; such laws prevent this population from receiving AIDS-related information say WHO officials.

Because of the relationship between poverty and AIDS, the WHO "global strategy thus calls for the social and economic empowerment of women."

\section{Sigmoidoscopic screening} proves effective in reducing the incidence of colorectal cancer, according to results from a study appearing in the March 5 issue of The New England Journal of Medicine.

In this case control, retrospective study, researchers at Kaiser Permanente Medical Care Program in Oakland, Calif, and the University of Washington, examined data on 261 persons who died of rectal cancer or distal colon cancer between 1971 and 1988 . The authors compared the use of screening via rigid sigmoidoscopy 10 years before the diagnosis of this cancer in this patient population with the use of such screening in 868 control subjects, matched for age and sex.

Slightly more than $24 \%$ of the control subjects had undergone sigmoidoscopic screening, compared with $8.8 \%$ of the study subjects. A negative association existed between (continued on page 565) 



\section{Bringing Together the Key Spectra of Two Antimicrobial Classes}

The Atypical Spectrum of Erythromycin ${ }^{1} \ldots$
Plus the Gram-Negative and GramPositive Spectra of the Beta-lactams ${ }^{1}$

\begin{tabular}{|l|c|c|c|c|c|}
\hline & Mycoplasma & H. influenzae & S. pneumoniae & $\begin{array}{c}\text { S. pyogenes } \\
\text { (group A strep) }\end{array}$ & M. catarrhalis \\
\hline BIAXIN1 & $\checkmark$ & $\checkmark$ & $\checkmark$ & $\checkmark$ & $\checkmark$ \\
\hline Erythromycin $^{2}$ & $\checkmark$ & & $\checkmark$ & $\checkmark$ & $\checkmark$ \\
\hline Amoxicillin $^{2}$ & & $\checkmark$ & $\checkmark$ & $\checkmark$ & \\
\hline Augmentin $^{\circledast 2}$ & & $\checkmark$ & $\checkmark$ & $\checkmark$ & $\checkmark$ \\
\hline Ceclor $^{\circledast 2}$ & & $\checkmark$ & $\checkmark$ & $\checkmark$ & $\checkmark$ \\
\hline Ceftin $^{\circledast 2}$ & & $\checkmark$ & $\checkmark$ & $\checkmark$ & $\checkmark$ \\
\hline
\end{tabular}

\section{Reliable Bioavailability}

- Excellent tissue penetration - without sacrificing therapeutic serum levels ${ }^{1,3}$

- Can be taken with or without food ${ }^{1}$ 


\section{Excellent Clinical Success Rates ${ }^{\star 11,4,5}$}

Community-Acquired Pneumonia

(typical and atypical)

Bronchitis

$(n=121) \quad 97 \%$

Pharyngitis

$(n=85) \quad 94 \%$

$(n=222) \quad 97 \%$

Acute Maxillary Sinusitis

\begin{tabular}{ll}
$(n=33)$ & $91 \%$ \\
\hline
\end{tabular}

\section{As Effective as Ceclor, Ceftin, and Suprax ${ }^{\circledR}$ in Eradicating $H$. influenzae in Well-Controlled Bronchitis Studies'}

\section{Very Well Tolerated}

- Significantly less GI upset than erythromycin - equivalent to beta-lactams such as amoxicillin, Ceclor ${ }^{\circ}$, and Ceftin ${ }^{\circ}, 5$

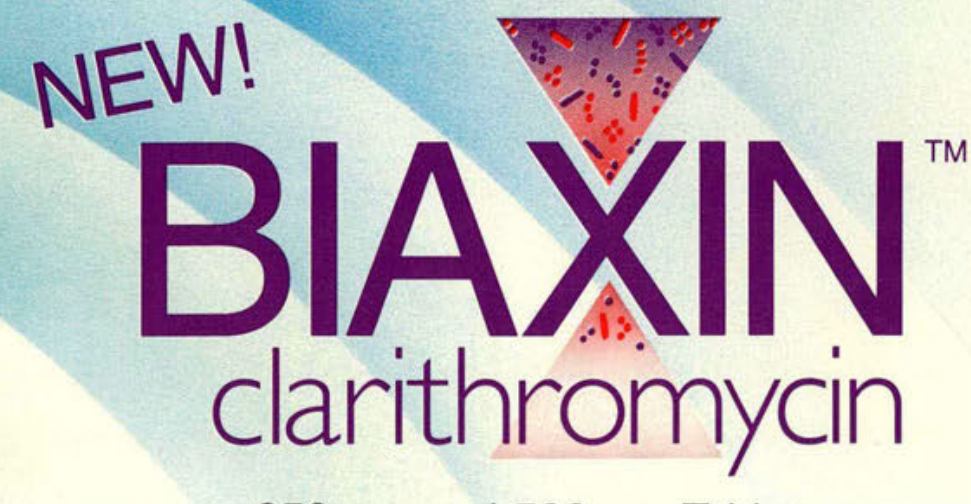

$250 \mathrm{mg}$ and $500 \mathrm{mg}$ Tablets

Spans the spectrum of erythromycin and the beta-lactams 


\section{Convenient BID Dosing Without Regard to Meals}

\begin{tabular}{|l|c|c|}
\hline \multicolumn{3}{|c|}{ Recommended Dosage } \\
\hline INFECTION & DOSAGE & DURATION \\
\hline $\begin{array}{l}\text { Lower Respiratory } \\
\text { Tract Infections: } \\
\text { Pneumonia/Bronchitis }\end{array}$ & $250-500 \mathrm{mg}$ BID & $7-14$ days \\
\hline $\begin{array}{l}\text { Upper Respiratory } \\
\text { Tract Infections: } \\
\text { Pharyngitis/Tonsillitis/ } \\
\text { Acute Maxillary Sinusitis }\end{array}$ & $250-500 \mathrm{mg}$ BID & $10-14$ days \\
\hline
\end{tabular}

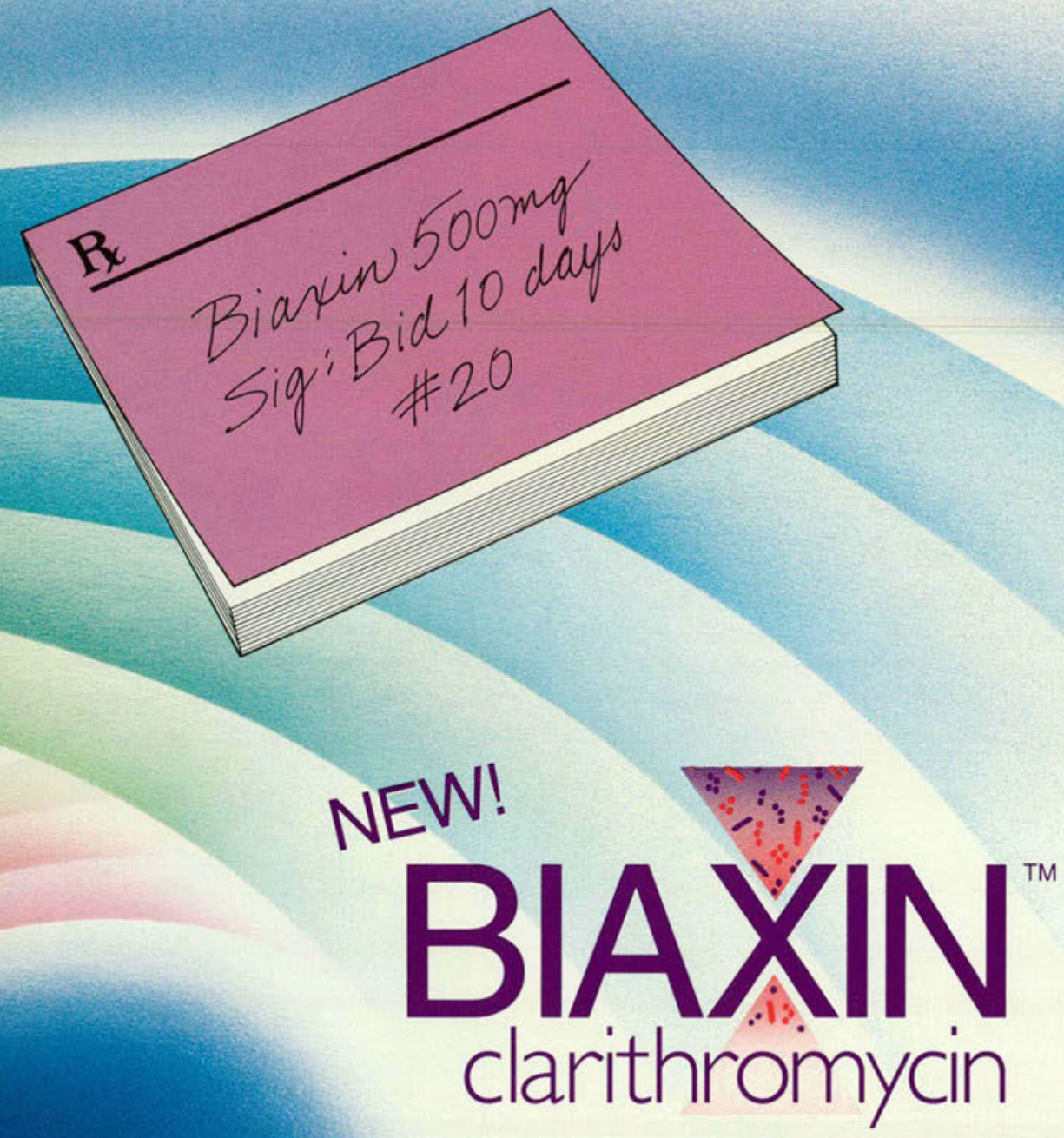

Spans the spectrum of erythromycin and the beta-lactams
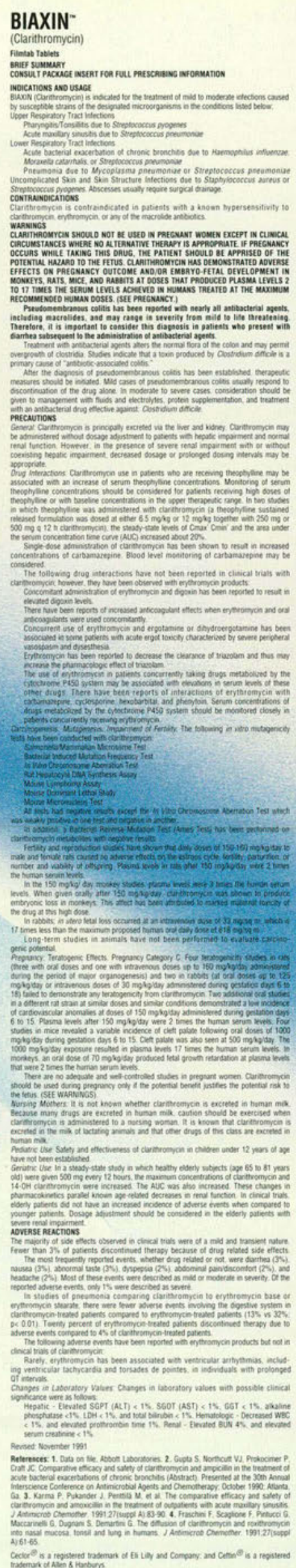
editorial comments

(continued)

the last sigmoidoscopic examination, which had occurred 9 to 10 years before actual diagnosis and more recent examinations.

"Our data suggest that sigmoidoscopy is among the most efficacious of screening tests," says lead author Joe V. Selby, MD. Dr Selby noted that such screening could reduce the overall death rate by at least $30 \%$.

Decreased choline levels in brain cell membrane phospholipids have been linked to Alzheimer's disease.

Researchers at the Massachusetts Institute of Technology found that choline levels were $40 \%$ to $50 \%$ lower in persons with Alzheimer's disease than in healthy individuals, as well as persons with Huntington's disease, Parkinson's disease, and Down syndrome. The number of choline molecules in Alzheimer's disease patients was also reduced, compared with the number of choline molecules in persons with the other aforementioned diseases.

Since the 1970 s, scientists have known that acetylcholine deficiency occurs in Alzheimer's disease patients. Acetylcholine, produced by choline, transmits signals between neurons and is also important in memory functions. A choline deficiency, then, af- fects the production of brain cell membrane phospholipids and acetylcholine levels.

Researchers hope that this latest discovery will enable physicians to diagnose Alzheimer's disease early in its course by measuring cholinerelated levels in spinal fluid.

These findings might also lead to medication for treating or arresting Alzheimer's disease. Such medication could include lecithin or potassium channel blockers, both of which increase choline production, and in the case of the latter, increase the release of acetylcholine.

\section{Over-the-counter (OTC)} drugs are not being closely monitored by the Food and Drug Administration (FDA), according to a study conducted by the General Accounting Office (GAO).

The GAO report found that the FDA collects less surveillance information and analyzes the performance of nonprescription drugs less frequently than for prescription drugs. Furthermore, unlike the situation with prescription drug companies, FDA inspectors lack the authority to check the records of OTC drug companies.

Although the FDA estimates that 125,000 to 300,000 OTC drugs exist in the marketplace, the GAO report cites (continued on page 567)

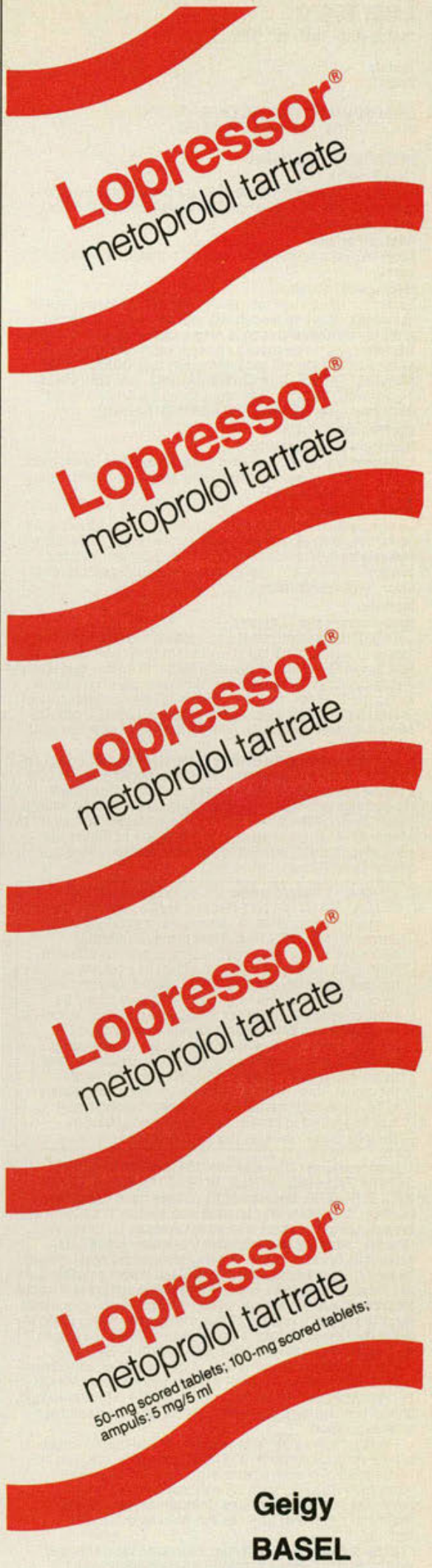

100-mg scored tablets 50-mg scored tablets 


\section{Lopressor $^{8}$}

metoprolol tartrate USP

Tablets
Ampuls

BRIEF SUMMARY (FOR FULL PRESCRIBING

INFORMATION, SEE PACKAGE INSERT

\section{IMDICATIONS AND USAGE}

Hypertension sion. They may be used alone or in combination with other antihypertensive agents.

Angina Pectoris

Angina Pectoris pectoris.

Myocardial Infarction

Lopressor ampuls and tablets are indicated in the treatment of hemodynamically stable patients with definite or suspected acute myocardial infarction to reduce cardiovascular mortaility. Treatment with intravenous Lopressor can be initiated as soo as the patient's clinical condition allows (See DOSAGE AND
ADMINISTRATION, CONTRAINDICATIONS, and WARNINGS) Alt Alternatively, treatment can begin within 3 to 10 days
acute event (see DOSAGE AND ADMINISTRATION)

CONTRAINDICATION

\section{Hypertension and Angina}

Lopressor is contraindicated in sinus bradycardia, heart block greater than first degree, cardiogenic shock, and overt cardiac lailure (see WARNiNGS).

opressor is contraindicated in patients with a heart rate $<45$ beats / $\mathrm{min}$; second-and third-degree heart block: significant first-degree heart block (P-R interval $\geq 0.24 \mathrm{sec}$ ); systolic blood pressure < $100 \mathrm{mmHg}$; or moderate-to-severe cardiac failure (see WARNINGS)

\section{WARNINGS}

\section{Hypertension and Angina}

Cardiac Fallure: Sympathetic stimulation is a vital component supporting circulatory function in congestive heart failure, and beta blockade carries the potential hazard of further depressin myocardial contractility and precipitating more severe failure. In hypertensive and angina patients who have congestive hear failure controlled by digitalis and diuretics, Lopressor should failure controlled by digitalis and diuretics, Lopressor should

In Patients Without a History of Cardiac Failure: Continued depression of the myocardium with beta-blocking agents over period of time can, in some cases, lead to cardiac failure. At the first sign or symptom of impending cardiac failure, patient should be fully digitalized and/or given a diuretic. The response spite adequate digitalization and diuretic therapy, Lopressor spite adequate digitalizat
should be withdrawn.

Ischemic Heart Disease: Following abrupt cessation of therapy with certain beta-blocking agents, exacerbations tion have occurred. When discontinuing chronically administered Lopressor, particularly in patients with ischemic heart disease, the dosage should be gradually reduced over a period of 1-2 weeks and the patient should be carefully monitored. If angina markedly worsens or acute coronary insutficiency develops, Lopressor adm istration should be reinstated promptly, at least tem porarily, and other measures appropriate for the management of unstable angina should be taken. Patients should be warned against interruption or discontinuation of therapy without the physician's advice. Because coronary artery disease is common and may be unrecognized, it may be prudent not to discontinue Lopressor therapy

Bronchoseastic Diseases: PATIENTS WITH BRONCHO. SPASTIC DISEASES SHOULD, IN GENERAL, NOT RECEIVE BETA BLOCKERS. Because of its relative beta selectivity. ronchospastic disease who do not respond to, or cannot olerate, other antihypertensive treatment. Since beta selectivity is not absolute, a beta ${ }_{2}$-stimulating agent should be administered concomitantly, and the lowest possible dose of Lopressor should be used. In these circumstances it would be prudent initially to administer Lopressor in smaller doses avoid the higher plasma levels associated with the longe osing interval. (SEe DOSAGE AND ADMINISTRATION. Major Surgery: The necessity or desirability of withdrawin beta-blocking therapy prior to major surgery is controversial; the impaired ability of the heart to respond to reflex adrenergic stimuli may augm

gical procedures.

Lopressor, like other beta blockers, is a competitive inhibitor of beta-receptor agonists, and its effects can be reversed by administration of such agents, e.g.. dobutamine or isoproterenol. However, such patients may be subject to protracted severe hypotension. Difficulty in restarting and blockers.

Diabetes and Hypoglycemia: Lopressor should be used with caution in diabetic patients if a beta-blocking agent is required. Beta blockers may mask tachycardia occurring with sweating may not be significantly affected

Thyrotoxicosis: Beta-adrenergic blockade may mask certain clinical signs (e.9., tachycardia) of hyperthyroidism. Patients suspected of developing thyrotoxicosis should be managed carefully to avoid abrupt withdrawa

\section{Myocardial Infaretion}

Cardiac Failure: Sympathetic stimulation is a vital component supporting circulatory function, and beta blockade carries the potential hazard of depressing myocardial contractility and pre cipitating or exacerbating minimal cardiac failure.

During treatment with Lopressor, the hemodynamic status of the patient should be carefully monitored. If heart failure $O C$ curs or persists despite appropriate treatment, Lopressor should be discontinued.
Bradycardia: Lopressor produces a decrease in sinus heart rate in most patients; this decrease is greatest among patients with high initial heart rates and least among patients with low initial heart rates. Acute myocardial infarction (particularly in ferior infarction) may in itself produce significant lowering of the sinus rate. If the sinus rate decreases to $<40$ beats/min, particularly if associated with evidence of lowered cardiac out-
put, atropine $(0.25-0.5 \mathrm{mg})$ should be administered intravenously. If treatment with atropine is not successful, Lopressor should be discontinued, and cautious administration of isoproterenol or installation of a cardiac pacemaker should be considered.

AV Block: Lopressor slows AV conduction and may produce significant first- ( $P-R$ interval $\geq 0.26 \mathrm{sec})$, second-, or thirddegree heart block. Acute myocardial infarction also produces heart block

If heart biock occurs, Lopressor should be discontinued and atropine $(0.25-0.5 \mathrm{mg})$ should be administered intravenously. If treatment with atropine is not successful, cautious administration of isoproterenol or installation of a cardiac pacemaker should be considered

Hypotension: If hypotension (systolic blood pressure $\leq 90$ $\mathrm{mmHg}$ ) occurs, Lopressor should be discontinued, and the hemodynamic status of the patient and the extent of myocardial ous, pulmefefully assessed. Invasive monitoring of central venrequired. Appropriate therapy with fluids, positive inotropic agents, balloon counterpulsation, or other treatment modalitie should be instituted. If hypotension is associated with sinus bradycardia or AV block, treatment should be directed at rebradycardia or AV block,

Bronchospastic Diseases: PATIENTS WITH BRONCHO. SPASTIC DISEASES SHOULD, IN GENERAL, NOT RECEIVE BETA BLOCKERS. Because of its relative beta, selectivity, Lopressor may be used with extreme caution in patients with bronchospastic disease. Because it is unknown to what extent beta 2 -stimulating agents may exacerbate myocardial ischemia and the extent of infarction, these agents should not be used prophylactically. If bronchospasm not related to congestive heart failure occurs, Lopressor should be discon tinued. A theophylline derivative or a beta ${ }_{2}$ agonist may be of the patient. Both theophyiline derivatives and beta ${ }_{2}$ agonof the patient. Both theophyline derivatives and
ists may produce serious cardiac arrhythmias.

PRECAUTIONS

Genera

Lopressor should be used with caution in patients with im paired hepatic function.

Patients should be advised to take Lopressor regularly and continuously, as directed, with or immediately following meals If a dose should be missed, the patient should take only the
next scheduled dose (without doubling it). Patients should not discontinue Lopressor without consulting the physician. Patients should be advised (1) to avoid operating automobiles and machinery or engaging in other tasks requiring alertness until the patient's response to therapy with Lopressor has been determined; (2) to contact the physician if any diffi-
culty in breathing occurs: (3) to inform the physician or dentist culty in breathing occurs; ( 3 to inform the physician or dent
before any type of surgery that he or she is taking Lopressor. Laboratory Tests

Clinical laboratory findings may include elevated levels of serum transaminase, alkaline phosphatase, and lactate dehydrogenase.

\section{Drug Interactions}

drugs (e.g., reserpine) may have an additive eflect when given with beta-blocking agents. Patients therefore be closely observed for evidence of hypotension or
marked bradycardia, which may produce vertigo, syncope, or

postural hypotension.
Risk of Anaphylactic Reaction. While taking beta-blockers, patients with a history of severe anaphylactic reaction to a variety of allergens may be more reactive to repeated chal patients may be unresponsive to the usual doses of epinephrin used to treat allergic reaction.

Carcinogenesis, Mutagenesis, Impairment of Fertility Long-term studies in animals have been conducted to evaluate carcinogenic potential. In a 2-year study in rats at three ora dosage evels of up to $800 \mathrm{mg} / \mathrm{kg}$ per day, there was no in-

crease in the development of spontaneously occurring benign or malignant neoplasms of any type. The only histologic changes that appeared to be drug reiated were an increased incidence of generally mild focal accumulation of foamy machyperplasia. In a 21 -month study in Swiss albino mice at three oral dosage levels of up to $750 \mathrm{mg} / \mathrm{kg}$ per day, benign lung tumors (small adenomas) occurred more frequently in female mice receiving the highest dose than in untreated control animals. There was no increase in malignant or total (benign plus malignant) lung tumors, nor in the overall incidence of tumors or malignant tumors. This 21-month study was repeated in CD-1 mice, and no statistically or biologically significant difeither sex for any type of tumer.

All mutagenicity tests performed (a dominant lethal study in mice, chromosome studies in somatic cells, a Salmonella mammalian-microsome mutagenicity test, and a nucleus

anomaly test in somatic interphase nuclei) were negative. No evidence of impaired fertility due to Lopressor was ob-
served in a study performed in rats at doses up to 55.5 times the maximum daily human dose of $450 \mathrm{mg}$.

Pregnancy Category C

Lopressor has been shown to increase postimplantation loss and decrease neonatal survival in rats at doses up to 55.5 times the maximum daily human dose of $450 \mathrm{mg}$. Distribution studies in mice confirm exposure of the fetus when Lopressor administered to the pregnant animal. These studies have revealed no evidence of impaired fertility or teratogenicity. There are no adequate and well-controlled studies in pregnant women. Because animal reproduction studies are not always predictive of human response, this

\section{Nursing Mothers}

Lopressor is excreted in breast milk in very small quantity. An infant consuming 1 liter of breast milk daily would receive a dose of less than $1 \mathrm{mg}$ of the drug. Caution should be exercised when Lopressor is administered to a nursing woman.

Pediatric Use

Safety and effectiveness in children have not been established. ADVERSE REACTIONS

Hypertension and Angina

Mst adverse effects have been mild and transient.

Central Nervous System: Tiredness and dizziness have

occurred in about 10 of 100 patients. Depression has been short-term memory loss have been reported. Headache, nightmares, and insomnia have also been reported.

Cardiovascular: Shortness of breath and bradycardia have occurred in approximately 3 of 100 patients. Cold extremities: arterial insufficiency, usually of the Raynaud type; palpitations; congestive heart failure; peripheral edema; and hypotension

have been reported in about 1 of 100 patients. (See CON

Respiratory: Wheezing (bronchospasm) and dyspnea have

Gastrointestinal: Diarrhea has occurred in about 5 of 100

patients. Nausea, dry mouth, gastric pain, constipation,
flatulence, and heartburn have been reported in about 1 of 100 patients.

Hypersensitive Reactions: Pruritus or rash have occurred in reported.

Miscellaneous: Peyronie's disease has been reported in fewer than 1 of 100,000 patients. Musculoskeletal pain, blurred vision, and tinnitus have also been reported.

There have been rare reports of reversible alopecia,

agranulocytosis, and dry eyes. Discontinuation of the drug

explicable.

The oculomucocutaneous syndrome associated with the beta blocker practolol has not been reported with Lopressor.

\section{Myocardial Infarction}

Central Nervous System: Tiredness has been reported in about 1 of 100 patients. Vertigo, sleep disturbances, hallucinations, headache, dizziness, visual disturbances, confusion,

tionship is not clear.

Cardiovascular in the randomized comparison of Lopressor and placebo described in the CLINICAL PHARMACOLOGY SeCtion, the following adverse reactions were reported:

$$
\begin{aligned}
& \text { Hypotension } \\
& \text { (systolic BP } \\
& <90 \mathrm{mmHg} \text { ) }
\end{aligned}
$$

Bradycardia

$<40$ beats $/ \mathrm{min}$

third-degree

third-degree

First-degree

( $P$ - $R \geq 0.26 \mathrm{sec})$

Heart failure

\section{Respirator}

$27.5 \%$

ported in fewer - Oyspnea of pulmonary

Gastrointestinal: Nausea and abdominal pain have been

eported in fewer than 1 of 100 patients.

Dermatologic: Rash and worsened psoriasis have been re-

ported, but a drug relationship is not clear

Miscellaneous: Unstable diabetes and claudication have been reported, but a drug relationship is not clear.

Avariety of adverse reactions not listed above have been re-

ported with other beta-adrenergic blocking agents and should

considered potential adverse reactions to Lopressor.

progressing to catatonia; an acute reversible syndrome charac- 
the agency's "inability to provide a precise or even a usable estimate" regarding the exact number of such products as one of its shortcomings.

Said Rep (D-Ore) Ron Wyden, who requested the study, "The FDA has little data regarding the type, prevalence, and cause of adverse reactions involving OTCs." Wyden also charged that in 30 years the agency has completed only $50 \%$ of the drug reviews that Congress ordered.

Mothers can correctly identify their newborns by just the touch of their child's hands, nearly $70 \%$ of the time, say Israeli researchers.

Researchers at the Hebrew University and the Shaare Zedek Medical Center in Jerusalemblindfolded 46 mothers and tested their ability to identify their own infant out of a group of three sleeping infants. The mothers had spent at least 1 hour with their newborn infants after they were born. Testing took place 5 to 79 hours after the mothers gave birth.

In touching the infants' hand (dorsal side), the mothers were guided by the experimenter. The blindfold covered each mother's eyes and nose. If the infants cried during the experiment, the experiment was discontinued until the infants were quieted and the or- der in which they were presented to the mother was changed. These procedures were taken to ensure that other sensory factors-smell and sound-did not influence the results.

Parity had no bearing on the mother's ability to discriminate between her infant and the other two newborns. However, exposure time did affect this tactile identification. Mothers who had spent less than 1 hour with their newborns could not correctly identify their own infant. Yet, those mothers who spent more than 10 hours with their infants had no advantage over those mothers who spent less time.

"We were very surprised with the results," says $\mathrm{He}$ brew University psychology professor and researcher Marsha Kaitz. "The women themselves were surprised."

Despite these results, researchers could not determine exactly what skin characteristics enabled the new mothers to correctly identify their child.

Although frequency and duration of touch have previously been identified as a factor in maternal attachment, this experiment shows that contact with a newborn's skin provides enough information by itself for the mother to identify her own child.

Complete study results appear in the March issue of $D e$ velopmental Psychology.
Pedia-Profen

Pedia-Profen

Pedia-Profen Pedia-Profen Pedia-Profen Pedia-Profen Pedia-Profen Pedia-Profen Pedia-Profen Pedia-Profen Pedia-Profen Pedia-Profen Pedia-Profen Pedia-Profen Pedia-Profen Pedia-Profen Pedia-Profen I ia-Profen P. ia-Profen a-Profen

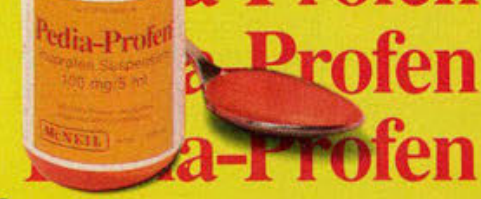

${ }^{\text {RT Pedia-Profen }}$ Ibuprofen Suspension $100 \mathrm{mg} / 5 \mathrm{ml}$ 


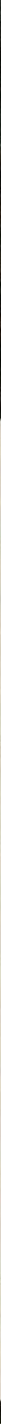

\section{Greater safety}

Topical application alleviates concerns about organ toxicity or drug interactions with concomitant therapy.

\section{Unique mode of action}

Zostrix contains capsaicin which depletes substance P, a neurotransmitter known to exacerbate pain and inflammation in arthritic joints. ${ }^{2}$ Through this mechanism, Zostrix provides pain control as monotherapy or enhances the efficacy of systemic regimens.

\section{Zostrix Cream}

(Capsaicin $0.025 \% \mathrm{~W} / \mathrm{w}$ )

\section{References}

1. Enhanced pain control in patients with osteoarthritis and rheumatoid arthritis following treatment with GenDerm Corporation, Northbrook, IL 60062 .

2. Harris ED. Rheumatoid arthritis: pathophysiology and implications for therapy. New England Journal of 


\section{cream

Double-blind, randomized, placebo-controlled

multicenter trial $(n=101)^{1}$

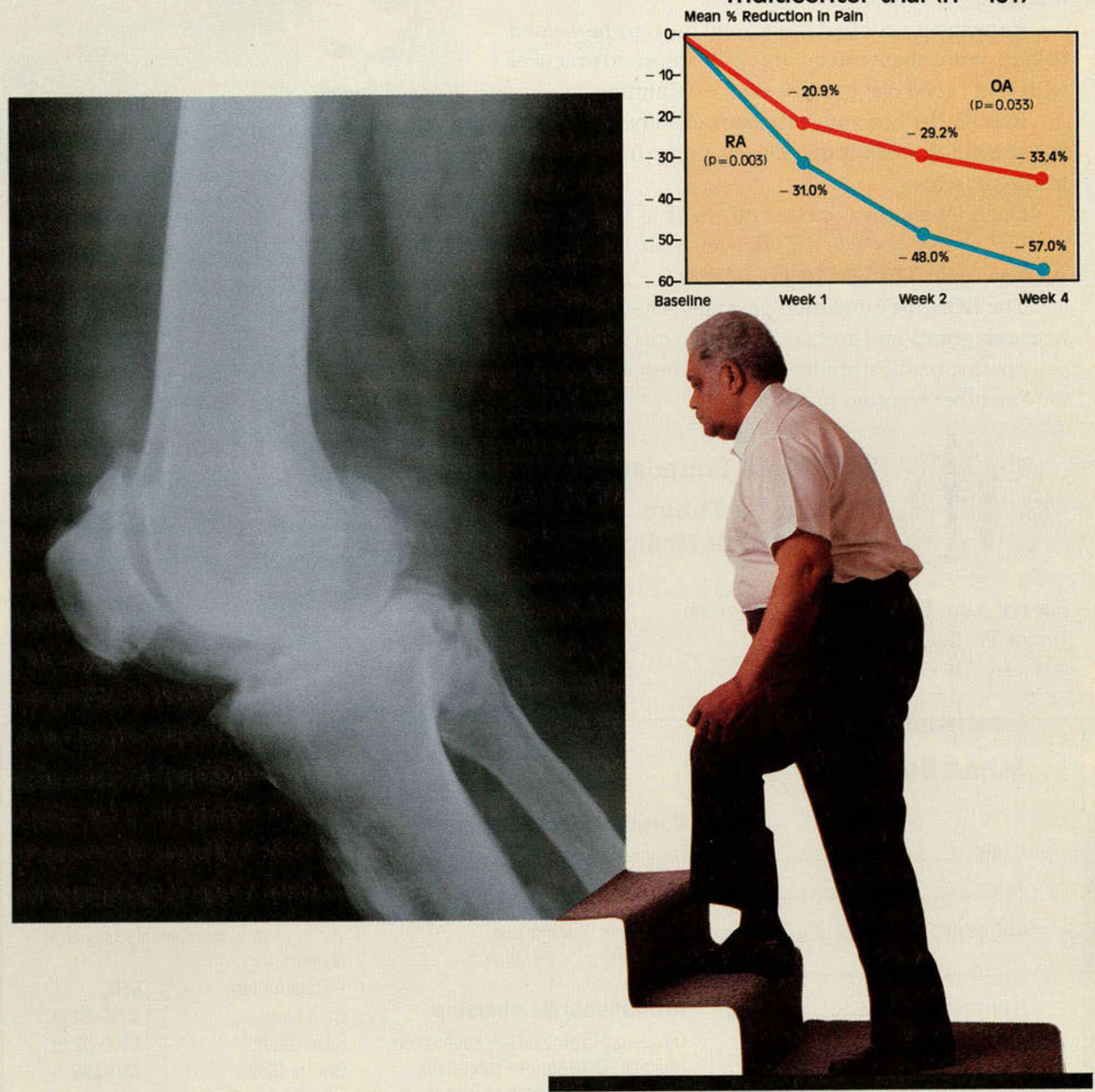

Zostrix icapalcn o.ess w/m Cream

\section{Topical Analgesic}

Description: Zostrix Cream contains capsaicin, $0.025 \%$ w/w in an emollient base containing benzyl alcohol, cetyl alcohol, glyceryl monostearate, isopropyl myristate, polyoxyethylene stearate blend, purified water, sorbitol solution and white petrolatum. Capsaicin is a naturally occurring substance derved from plants of the solanaceae famiy with the capsicin awhite of 305.4 . It is practical ly insoluble in water butvery soluble in alcohol, ether and ch oroform.

Action: Although the precise mechanism of action of capsaicin is not fully understood, current evidence suggests that capsaicin renders skin and joints insensidve to pain by depleting and preventing reaccumulation of substance pl the principal chemomediator of pain impulses from the periphery to the central nervous system in addition and activate inflammatory mediators involved with the pathogenesis of rheumatoid arthritis.

Indication: Zostrix is indicated for the temporary relief of peripheral neuraiglas such as the pain following shingles ellef of the pain associated with rheumatoid arthritis and osteoarthritis.

Warnings: FOR EXTERNAL USE ONLY. Avoid contact with eyes and broken or irritated skin. Do not bandage tignty. if

condition worsens, or does not improve after 28 days.

discontinue use of this product and consult your physician. keep this and all drugs out of the reach of chlidren. in
Directions: Adults and children 2 vears of age and older: burning may occur upon application, but usually disappears in 72 hours. Application schedules of less than 3 to 4 timesa day may not provide optimum pain relief and the burning .

How Supplied

15 oz tube (NDC 52761-552-45)

3.0 oz tube (NDC 52761. 552.85 )

U. Patent NOS. 4486450 and 5536404

coris 


\section{Remember back when you were "just" an osteopathic medical student...?}

Remember when you wanted to do that special preceptorship...or that time when you wanted to do that research project that truly might have benefited mankind.

Remember your best friend, and the time he wanted to learn more about osteopathic principles and practices with that "good ole' country doc" in Montana.

Remember how much that one classmate of yours, the straight-A student that always sat up front, wanted to stay in school.

Don't let another osteopathic medical student remember the way you did. Become part of the solution...join The SOMA Foundation.

The SOMA Foundation provides scholarships, research grants and special preceptorship stipends to osteopathic medical students so that they won't have to remember wanting to... they will.

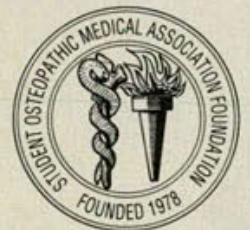

\section{The SOMA Foundation}

Building the Future of Osteopathic Medicine Today

Karoly John Dobay, III, Chairperson James W. Sego, Director Gregory Toci, Treasurer

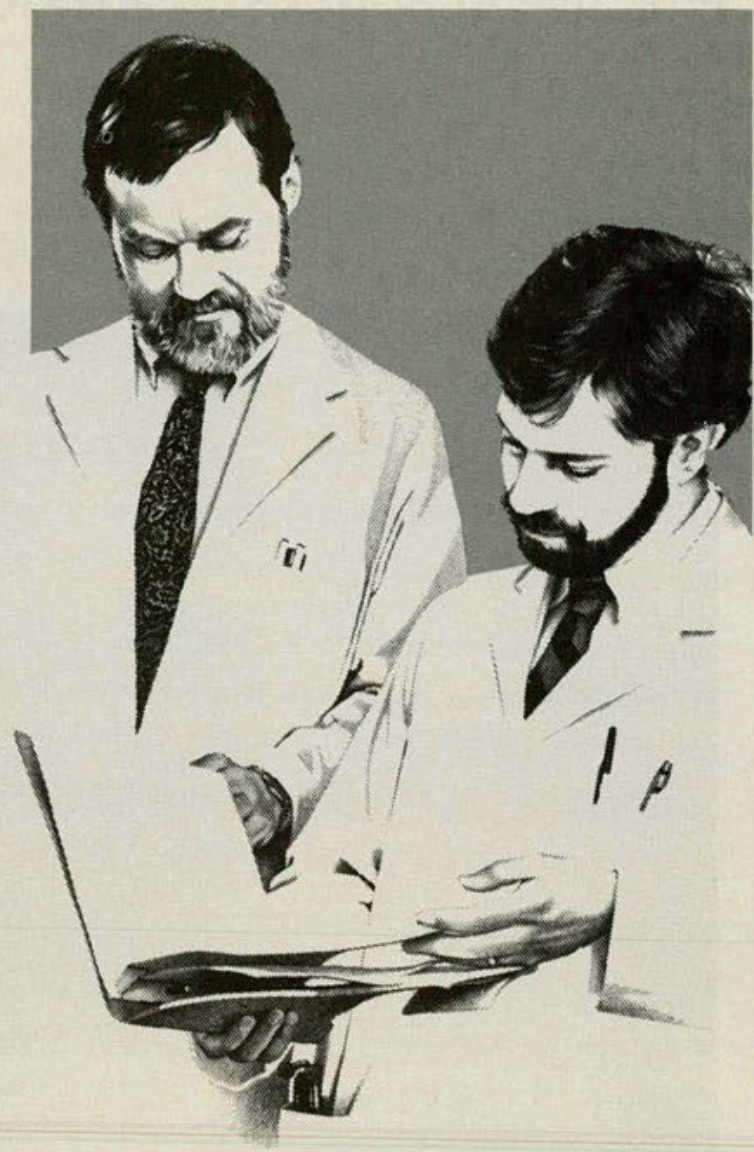

DETACH HERE

\section{SOMA Benefactor Card}

Name:

Title:

Company:

Address:

Phone:

Make checks payable to: The SOMA Foundation.

Tax Exemption Number: 36-296-7404.

For more information, call 1 (800) 237-SOMA

\section{Corporate Membership:}

Designed to provide your company with the highest visibility and best line of communication to the osteopathic physicians of tomorrow.

$\square \$ 2,000 \quad \square$ Other $\$$

\section{Institutional Membership}

Developed to provide any Foundation,

Hospital, College, or Professional

Association/Organization with the

highest visibility and best line of communication to the osteopathic physicians of tomorrow through various Clubs which feature varying yearly membership fees.

Diamond Club:

Ruby Club:

$\$ 2,000$

$\$ 1,000$ $\$ 1,999$

Emerald Club: $\$ 250-\$ 999$

Other:

\section{Individual Membership}

Designed to provide individuals with maximum personal recognition through various Clubs which feature varying yearly membership fees and benefits.

Platinum Club: $\quad \square \$ 500$

Gold Club: $\$ 250-\$ 499$

Silver Club: $\$ 100-\$ 249$

Bronze Club: $\$ 50-\$ 99$

Well-Wisher Club: Other: $\$ 25-\$ 49$ $\$$

Please detach and mail to: The SOMA Foundation 142 East Ontario Street Chicago, IL 60611 
